\title{
Effect of preparation of wood raw materials and some processing modes on the output of liquid pyrolysis products
}

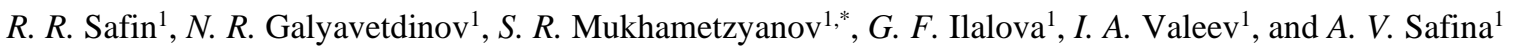 \\ ${ }^{1}$ Kazan National Research Technological University, Kazan, Russia
}

\begin{abstract}
Today, the limitations of traditional energy sources based on oil, natural gas and coal are becoming obvious. Therefore, the search for new sources of energy is a pressing issue both for modern Russia and for the whole world. The alternative sources of energy, based on the use of bioenergy of biomass, begin to play a significant and growing role in the world energy industry. The article presents the curves of changes in the mass yield of products obtained during the pyrolysis of biomass, thermally pretreated in the temperature range of $180-270{ }^{\circ} \mathrm{C}$ without access of oxygen. It has been experimentally proved that pre-heat treatment reduced the total liquid yield in the pyrolysis process: with an increase in the processing temperature, the mass yield of the liquid decreased, but the mass yield of charcoal and gas changed slightly. At the same time, it was found that the temperature affected the yield of the elemental composition of biomass: as the temperature increased, the content of elemental carbon in the biomass increased, while the content of hydrogen and oxygen decreased. It is concluded that the preliminary heat treatment of biomass can improve the quality of the final liquid biofuel by reducing the water content in it and by increasing the heat of combustion. It is also found that pressure reduction during the pyrolysis process increased the yield of the liquid fraction of decomposition products.
\end{abstract}

\section{Introduction}

There is a huge amount of plant waste from the production of grain, oilseeds and other crops in Russia every year, which adversely affects land and water resources. In this regard, the active searches for methods of efficient use of waste of annual crops are going on all over the world. The plant biomass, which is constantly renewed in the process of photosynthesis and exceeds the total production of coal, oil and gas can be a promising raw material for the production of a number of useful substances and materials. At the same time, to create effective technologies for processing of plant materials, complete and reliable information on the physico-mechanical and sorption characteristics is needed, as well as on the chemical composition of the substances of the plant, which are often absent.

One of the most common and important application areas of plant waste is biofuel. In recent years, research has been conducted in the field of obtaining biochar - a porous high-carbon product. One of the main methods for producing biochar is the pyrolysis of biomass (thermal decomposition of biomass without oxygen), which is the main thermochemical process of converting biomass into more useful fuel. It should be noted that the technology of creating this product is environmentally friendly, because it proceeds without the use of chemicals, and the decomposition products of biomass released during pyrolysis are also fully captured and used as biofuel. As a result, the biomass is heated without oxygen or partially burned in a small amount of oxygen to obtain a hydrocarbon-rich gas mixture, an oily liquid, and a carbon-rich solid residue. The yield of products obtained during the pyrolysis of biomass mainly depends on the chemical composition of raw materials and operating temperature. The resulting liquid can also be used as a fuel or for the production of chemicals and other products. Depending on the conditions, the pyrolysis processes can be divided into three subclasses: ordinary pyrolysis, fast pyrolysis and instant pyrolysis.

A lot of works of famous scientists all over the world have been sent to the research of pyrolysis processes. For example, researchers found in the 1980s that the yield of pyrolysis fluid could be increased by using fast pyrolysis, when biomass feedstock heated up at a high speed, and the produced pairs also quickly condensed. Thus, fast pyrolysis can be applied to obtain the maximum amount of either a liquid or a gas, depending on the set process temperature $[1,2]$.

The authors of [3] investigated the high-temperature fast pyrolysis of wood, rice husk and forest wood residues, which was carried out in a fixed-bed laboratory reactor. The results were compared with the pyrolysis of biomass samples carried out in another reactor under slow pyrolysis conditions. In the course of research, a noticeable difference was observed in the yield of products depending on the heating rate. Accordingly, much higher yields of oil and char were obtained as a result of rapid pyrolysis, whereas with slow pyrolysis the

\footnotetext{
* Corresponding author: joker775.87@mail.ru
} 
yield of bio oil was lower. The composition of the gaseous products was also influenced by the heating rate. In additional experiments the effect of pyrolysis temperature was investigated under conditions of rapid pyrolysis. It was found that the overall gas yield increased with increasing the temperature. The concentration of hydrogen gas increased with a decrease in the hydrocarbon content.

In recent years, studies of the pyrolysis process are aimed at improving the quality of thermochemical processing products. One of such areas is the preliminary heat treatment of wood raw materials (torrefaction) before the pyrolysis process. At the moment, it is known that torrefaction allows increasing the calorific value of biomass.

S S Vincent, N Mahinpey and T Mani conducted the studies of heat treatment of biomass, the effect of temperature, particle size, and residence time on torrefaction of flax straw [4]. As a result, the analysis of the semi-coke remaining after firing showed a significant increase in the fixed carbon and ash content, as well as a noticeable decrease in the moisture and volatile substances with increasing temperature. The results of the final analysis showed that the maximum carbon yield was about $61 \%$, and its heat of combustion increased to $24 \times 10^{3} \mathrm{~kJ} / \mathrm{kg}$ for larger particles $(1200 \mathrm{~mm})$, which were treated at $300{ }^{\circ} \mathrm{C}$. The kinetic analysis showed the activation energy of $76.64 \mathrm{~kJ} / \mathrm{mol}$ for a particle size of $925 \mathrm{~mm}$ and a time of 60 minutes. The authors have found that the greatest influence on the firing process had a temperature, rather than the residence time or particle size.

Also, the effect of roasting on the characteristics of the raw materials of tropical biomass (rice husks, peanut shells and corn cobs) was investigated at different roasting temperatures $[5,6]$. Rice husks and corn cobs showed a more intensive weight loss during torrefaction due to the high degradation of hemicelluloses inherent raw materials. The carbon of the torrefied biomass obtained from the final analysis showed a low and concentrated distribution.

An analysis of literary studies has shown that pyrolysis and torrefication of biomass were quite relevant research directions throughout the world. The mankind finally understood that natural reserves of coal and gas were not limitless and would run out sooner or later [7]. The world can either face a huge technological catastrophe or switch to the second generation fuel. Torrefication of biomass will help with solving this problem. However, despite this, there are still a lot of tasks and research that require a more detailed study of these processes. In particular, this article was tasked to investigate the effect of preliminary torrefaction of plant raw materials on subsequent pyrolysis and its products $[8,9]$.

\section{Methods and materials}

In order to study the pyrolysis of biomass and the influence of physical parameters on the output of biochar, liquid and gas, an experimental setup was developed and manufactured (Figure 1). It consists of pyrolysis chamber 1 , valve 2 , coil condenser 3 , shelland-tube condenser 4 with condensate collectors, a vacuum receiver 5 with a vacuum pump 6 , and liquid-jet ejectors 7 . The temperature in the pyrolysis chamber 1 is maintained at a predetermined value using a temperature controller 8, electric heaters 9, a thermocouple 10 and a switchboard 11. Pressure in the pyrolysis chamber 1 is recorded using a differential pressure gauge 12 . The change in mass of sample 13 during pyrolysis is

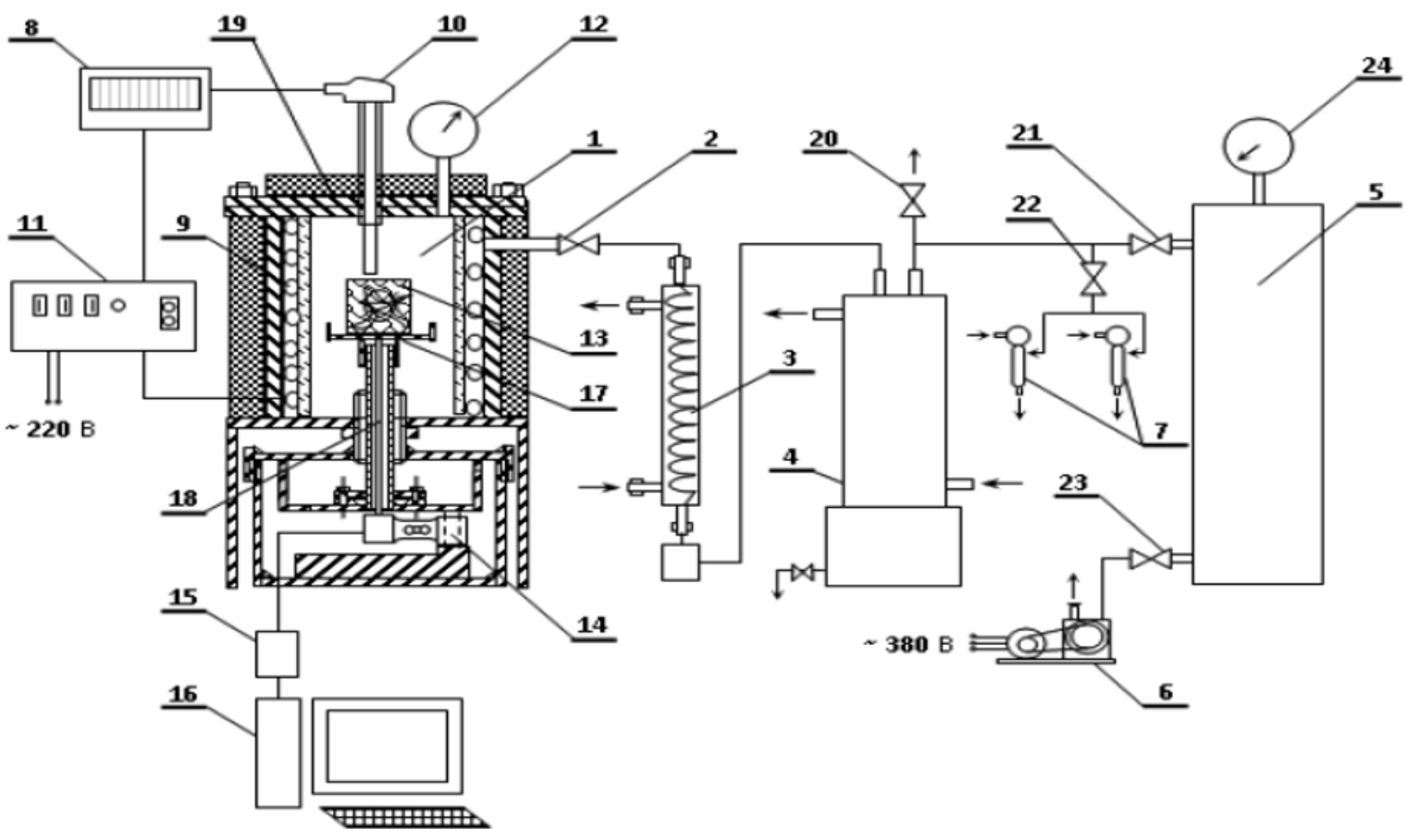

Fig. 1. The scheme of the experimental setup of wood pyrolysis. 
recorded using a strain gauge 14, the signal from which passes through the analog-digital converter 15 and enters the computer 16. The change in mass of the sample recorded by the sensor is saved in the database and is processed in real time. As a result of data processing, the duration of pyrolysis is determined.

Experimental studies are carried out as follows. The pre-weighed sample 13 is placed on a special bowl 17, the pressure of which is transferred to the strain gauge 14 by means of the rod 18 . After that, the pyrolysis chamber 1 is sealed by means of the cover 19 and the unit is turned on. According to the plan of the experiment the value of the pyrolysis temperature sets using the temperature controller 8 ; the pressure in chamber 1 is maintained at the set point manually by means of valve 2 and the pressure control system.

If it is necessary to conduct an experiment in a rarefied environment, ejectors 7 and a vacuum receiver 5 enter into operation. When conducting experiments under overpressure, valve 2 is closed until the required pressure is reached due to the liberation of volatile components and the temperature effect. Then the pressure is gradually released through valves 2 and 20 . The experiment ends with the stabilization of the sample mass, which indicates the end of the release of volatile substances. After that, the experimental setup is turned off and the charcoal is cooled naturally.

The experiments were carried out on birch wood samples preheated in the temperature range from 180 to $270{ }^{\circ} \mathrm{C}$ in the described chamber [10].

Thus, prototypes of decomposition products of woody biomass were obtained in the process of research work.

\section{Results}

In the course of the research, mass yields of solid and liquid media were calculated for each sample by analyzing the mass of liquid and coal collected on the total mass. The gas yield was determined by measuring the volume of exhaust gas during reactor feed, measured by gas chromatography flame ionization and thermal conductivity detector at sampling intervals.

According to the obtained research results, it can be noted that the preliminary heat treatment of biomass reduces the overall liquid yield during the pyrolysis process. Moreover, with an increase in the biomass processing temperature, the mass yield of the liquid decreases, but the mass yield of charcoal and gas practically does not change (Figure 2). That is explained by a lower moisture content in the incoming product.

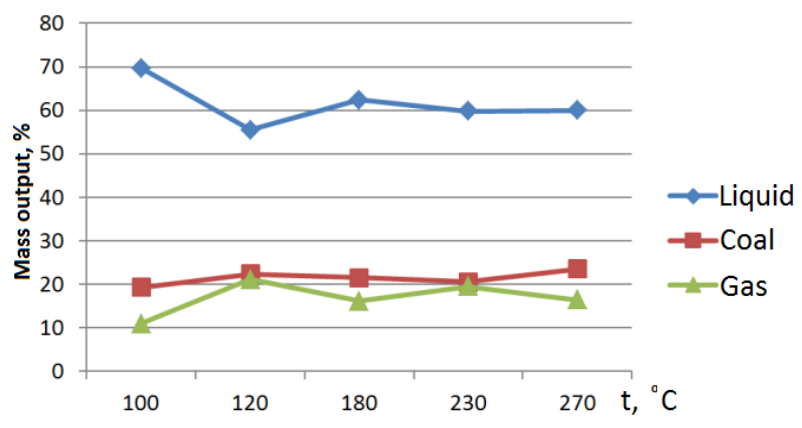

Fig. 2. Mass output of liquid, charcoal and gas with increasing temperature.

Further, studies on the pyrolysis products (bio-oil) were carried out. From the results it can be concluded that the water content in bio-oil obtained from thermally treated material is reduced compared with the content in the product from the mass. As a result, a lower concentration of water and a lower yield of the liquid fraction are obtained in the final product. However, the effect on the final water content in biomass or the mass yield of the liquid fraction does not correlate with the intensity of heat treatment. This corresponds to a higher mass yield of coal during the pyrolysis process with preliminary heat treatment. Comparing the different samples of this study it can be noted that these effects, observed during pyrolysis, are also due to the hemicellulose reaction at the preliminary heat treatment stage [11].

In addition to the above studies, an element-byelement analysis of the bio-oil composite was performed. As can be seen from the graph, as the processing temperature increases, the content of elemental carbon in the biomass increased, while the content of hydrogen and oxygen began to decline (Figure 3 ).

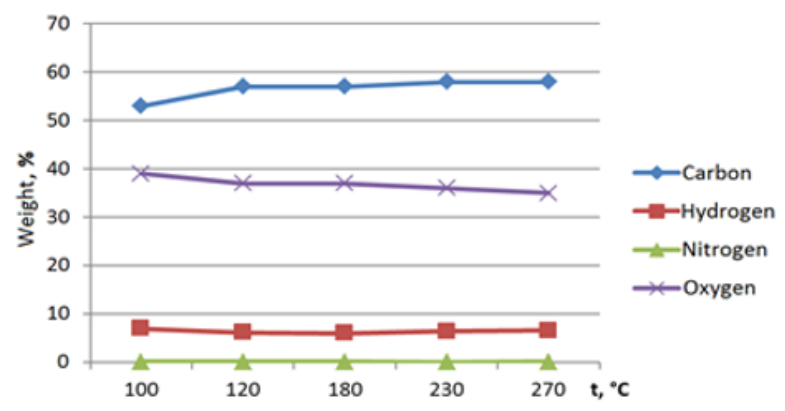

Fig. 3. Dry elemental analysis of bio-oil composite.

While the overall fluid output decreases, the quality of the fluid slightly increases. However, due to the fact that pyrolysis oil is an intermediate step in the conversion chain for liquid transport fuels, there are other factors that need to be considered to determine whether preheating can have an additional positive effect on the quality of the oil produced. A slight deoxygenation and a decrease in the acid content at the same time suggests that reactive oxygen-containing compounds in bio-oil, which impede catalytic renewal, are partially reduced due to the preliminary heat treatment of biomass before pyrolysis [12-15]. 


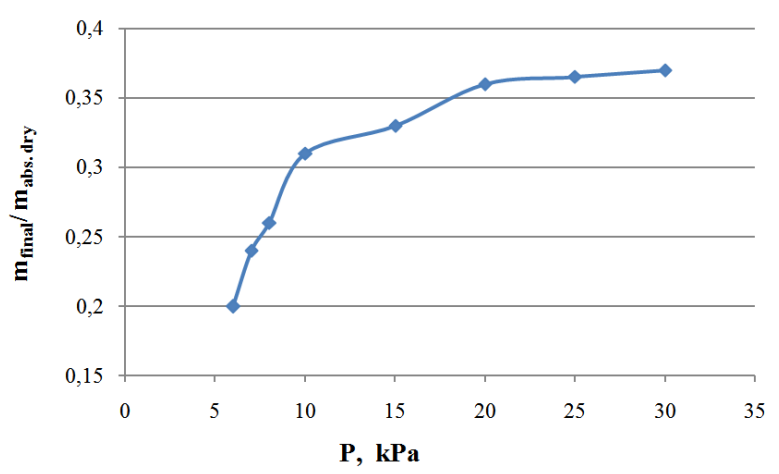

Fig. 4. The dependence of the biochar yield on the pressure in the chamber.

At the same time, an analysis of the dependence of biochar yield on the total pressure in the chamber (Figure 4) showed that an increase in pressure did not favor the decomposition of charring biomass products, but caused an intense temperature increase and prevented the output of the vapor-gas mixture. It subsequently contributes to greater biomass recombination and increase the yield of coal. The vacuum in the chamber also contributes to the growth of the yield of liquid products, due to their rapid removal from the reaction zone, without interacting with biochar - a strong catalyst for chemical reactions.

\section{Conclusions}

Thermochemical conversion plays an important role in the transformation of raw biomass into promising raw materials.

According to the results of the performed work it is revealed that preliminary heat treatment does not have a significant effect on the mass yield of pyrolysis products. However, there is an increase in the energy value of biooil due to changes in the elemental composition of biomass. At the same time, an analysis of the dependence of the biochar yield on the pressure in the chamber showed that a decrease in pressure favored the decomposition reaction of biomass charring products and contributed to an increase in the bio-oil yield.

\section{References}

[1] Fomin A.A., Limiting product surface and its use in profile milling design operations Solid State Phenomena 265, 672-8 (2017)

[2] R.R. Safin, I.F. Khakimzyanov, N.R. Galyavetdinov, S.R. Mukhametzyanov, Gasification of torrefied fuel at power generation for decentralized consumers IOP Conference Series: Earth and Environmental Science 87, 032035 (2017)

[3] Q.M.K. Waheed, M.A. Nahil, P.T. Williams, Pyrolysis of waste biomass: investigation of fast pyrolysis and slow pyrolysis process conditions on product yield and gas composition Journal of the Energy Institute 86, 233-41(2013)

[4] S.S. Vincent, N. Mahinpey, T. Mani, Torrefaction of flax straw biomass and its kinetic studies
Journal Energy Sources, Part A: Recovery, Utilization, and Environmental Effects 37, 2338-45 (2015)

[5] M.U. Garba, S.U. Gambo, U. Musa, K. Tauheed, M. Alhassan, O.D. Adeniyi, Impact of torrefaction on fuel property of tropical biomass feedstocks Biofuels 9, 369-77 (2016)

[6] S.R. Mukhametzyanov, R.R. Safin, P.A. Kainov, Alternative energy in the processes of drying of thermolabile materials International Multi-Conference on Industrial Engineering and Modern Technologies, FarEastCon 20188602648 (2018)

[7] R.R. Safin, A.S. Shaikhutdinova, R.R. Khasanshin, L.V. Akhunova, A.V. Safina, Improving the energy efficiency of solid wood fuel International Multidisciplinary Scientific GeoConference Surveying Geology and Mining Ecology Management 1, 315-22 (2015)

[8] R.R. Khasanshin, R.R. Safin, N.R. Galyavetdinov, Use of low-grade vegetable raw materials in production of composites by preliminary processing International Conference on Industrial Engineering 265, 296-302 (2017)

[9] R.R. Safin, R.R. Khasanshin, I.F. Khakimzyanov, S.R. Mukhametzyanov, P.A. Kainov, Increasing the energy efficiency of the process of oscillating vacuum-conductive drying of wood by means of a heat pump Journal of Engineering Physics and Thermophysics 90, 310-317 (2017)

[10] N.R. Galyavetdinov, R.R. Safin, A.E. Voronin, A.R. Shaikhutdinova, The mathematical modeling of the wood greenery extraction processes In International Conference on Mechanical Engineering, Automation and Control Systems (MEACS) 1-4 (2015)

[11] R.R. Safin, A.E. Voronin, A.S. Shaikhutdinova, F.V. Nazipova, P.A. Kaynov, Method of rational use of waste of timber industries International Multidisciplinary Scientific GeConference Scientific GeConference Surveying Geology and Mining Ecology Management 1, 699-706 (2015)

[12] R.R. Safin, R.R. Khasanshin, S.R. Mukhametzyanov, Influence of technical parameters of disk-shaped reactor on productivity of heat treatment of crushed wood IOP Conference Series: Materials Science and Engineering 327042095 (2018)

[13] S. Czernik, A.V. Bridgwater, Overview of applications of biomass fast pyrolysis oil Energy Fuels 18, 590-598 (2004)

[14] A. Demirbas, Pyrolysis mechanisms of biomass materials Energ.Source A31 1186-1193 (2009)

[15] R.R. Safin, F.V. Nazipova, R.R. Khasanshin, A.E. Voronin, Pre-treatment of vegetable waste in the production of composite materials Key Engineering Materials 743, 53-9 (2017) 